\title{
Caffeine Induces High Expression of cyp-35A Family Genes and Inhibits the Early Larval Development in Caenorhabditis elegans
}

\author{
Hyemin Min $^{1,3}$, Ichiro Kawasaki ${ }^{1,3}$, Joomi Gong ${ }^{1}$, and Yhong-Hee Shim ${ }^{1,2, *}$
}

Intake of caffeine during pregnancy can cause retardation of fetal development. Although the significant influence of caffeine on animal development is widely recognized, much remains unknown about its mode of action because of its pleiotropic effects on living organisms. In the present study, by using Caenorhabditis elegans as a model organism, the effects of caffeine on development were examined. Brood size, embryonic lethality, and percent larval development were investigated, and caffeine was found to inhibit the development of $C$. elegans at most of the stages in a dosage-dependent fashion. Upon treatment with $30 \mathrm{mM}$ caffeine, the majority $(86.1 \pm 3.4 \%)$ of the L1 larvae were irreversibly arrested without further development. In contrast, many of the late-stage larvae survived and grew to adults when exposed to the same $30 \mathrm{mM}$ caffeine. These results suggest that early-stage larvae are more susceptible to caffeine than later-stage larvae. To understand the metabolic responses to caffeine treatment, the levels of expression of cytochrome P450 (cyp) genes were examined with or without caffeine treatment using comparative microarray, and it was found that the expression of 24 cyp genes was increased by more than 2 -fold $(p<0.05)$. Among them, induction of the cyp-35A gene family was the most prominent. Interestingly, depletion of the cyp-35A family genes one-by-one or in combination through RNA interference resulted in partial rescue from early larval developmental arrest caused by caffeine treatment, suggesting that the high-level induction of cyp-35A family genes can be fatal to the development of early-stage larvae.

\section{INTRODUCTION}

1,3,7-trimethylxanthine, commonly known as caffeine, is one of

1Department of Bioscience and Biotechnology, ${ }^{2}$ Institute of KU Biotechnology, Konkuk University, Seoul 143-701, Korea, ${ }^{3}$ These authors contributed equally to this work.

*Correspondence: yshim@konkuk.ac.kr

Received 24 October, 2014; revised 24 November, 2014; accepted November 25, 2014; published online 16 January, 2015

Keywords: caffeine, C. elegans development, microarray, RNA interference the most popular drugs in the world. It comes from coffee beans, tea leaves, kola nuts, cacao pods, and so on (Gilbert et al., 1976). People ingest caffeine in one form or another every day, and it has become very popular in our daily lives. Recently, caffeine consumption has been increasing even among teenagers. Caffeine is known to enhance physiological functions in humans including sharpening our mind, improving athletic performance, and many other health improvements (Reviewed in Weinberg and Bealer, 2002). However, caffeine is an addictive drug. Although its effects are milder than those of other addictive drugs such as amphetamines, cocaine, and heroin, overlapping channels mediate the signal (Nehlig, 1999), which means that caffeine can also cause medical concerns.

Research revealed that caffeine consumption both before and during pregnancy increased the risk of spontaneous abortion (Cnattingius et al., 2000) and births classified as 'small for gestational age' (Hoyt et al., 2014). Maternal caffeine intake of over $300 \mathrm{mg} /$ day doubled the risk of miscarriage compared with that of $151 \mathrm{mg} /$ day (Giannelli et al., 2003). Such results suggest that intake of high doses of caffeine during pregnancy is a risk factor for fetal growth retardation. Therefore, understanding the basis of developmental defects caused by caffeine intake is an emerging issue, considering the fact that caffeine is now intertwined in the daily life of most people. Caffeine is metabolized in the liver by cytochrome P450 (CYP450) and excreted as urine in mammals (Kot and Daniel, 2008). The half-life of caffeine ranges from 3 to $7 \mathrm{~h}$ in adult plasma. Interestingly, the half-life is prolonged during pregnancy, in which it can be more than 10 h (Knutti et al., 1981). In addition, neonates have a greatly reduced capacity to metabolize caffeine, and it is excreted into the urine in largely unmetabolized form until hepatic metabolism becomes activated (Brent et al., 2011). Mammals contain 51 CYP family members, which are grouped into 10 subfamilies (Nelson et al., 2004). Among them, CYP1 to CYP4 are the drug-metabolizing families, and caffeine has been shown to be metabolized by CYP1A2 in mammals (Kot and Daniel, 2008). CYP450s render drugs more water-soluble so they can be excreted more easily in the urine or bile, and thereby, the drugs are processed by oxidative metabolism. Thus, CYP450s are able to promptly reduce the effects of drugs. The reduced capacity of neonates to metabolize caffeine therefore suggests that insufficient neonatal cyp gene expression may be the cause of developmental defects after caffeine intake during pregnancy. Besides detoxification effect of cyp-35A genes, it was reported that CYPs could convert non-toxic chemicals to 
harmful chemicals in the body. For example, cytochromes P450 is known to convert some polycyclic aromatic hydrocarbons and polychlorinated biphenyls to ultimate carcinogenic metabolites (Shou et al., 1996), suggesting that induction of cyp genes may possibly cause toxic effects.

C. elegans is a simple organism, but its genomic DNA sequence is more than $40 \%$ similar to that of human (The C. elegans sequencing consortium, 1998). After the completion of genome sequencing, $C$. elegans became an even more powerful organism for the investigation of dynamic changes of multiple gene expressions using microarrays. In $C$. elegans, when worms were treated with less than $10 \mathrm{mM}$ of low-dose caffeine and with coffee extract (3.6 mM caffeine), they showed extended life span and protection against age-associated neurodegenerative diseases, respectively (Dostal et al., 2010; Sutphin et al., 2012). However, high-dose caffeine treatment reduced life span (Sutphin et al., 2012), suggesting that caffeine affects $C$. elegans development in a dosage-dependent fashion. In this study, the effects of caffeine on the development of $C$. elegans were examined, along with investigation of the effects of caffeine on global changes of the expressions of cyp genes in $C$. elegans through microarray analysis. There are approximately 80 cyp genes in the $C$. elegans genome (Menzel et al., 2001). Among them, genes of the cyp-35A subfamily were found to be induced most prominently by caffeine treatment in $C$. elegans. The biological roles of cyp genes during development were further examined by depleting the activity of $c y p-35 A$ family genes through RNA interference. Surprisingly, it appears that high-level induction of cyp-35A family genes during the early-larval stages of $C$. elegans development can be fatal.

\section{MATERIALS AND METHODS}

\section{C. elegans strain and maintenance}

Methods for the maintenance and handling of $C$. elegans were as previously described (Brenner, 1974). Strain N2 was used as the wild type for all analyses. Worms were maintained at either $15^{\circ} \mathrm{C}$ or $20^{\circ} \mathrm{C}$ on Nematode Growth Medium (NGM) agar plates containing Escherichia coli strain OP50 supplemented with $5 \mu \mathrm{g} / \mathrm{ml}$ of cholesterol. For caffeine treatment, appropriate amounts of caffeine (Sigma, USA) were included in the NGM agar plates before autoclaving to achieve final concentrations from 10 to $30 \mathrm{mM}$.

Analysis of brood size, embryonic lethality, and percent larval development

L4-stage N2 hermaphrodites were individually cloned onto either caffeine-containing or control NGM agar plates and grown at $20^{\circ} \mathrm{C}$. They were transferred to new plates in $24 \mathrm{~h}$ intervals for three days to allow embryo production. Laid embryos were considered dead if they did not hatch after $48 \mathrm{~h}$ at $20^{\circ} \mathrm{C}$. Brood size was calculated as the total number of nonhatched and hatched embryos produced by a single mother hermaphrodite. Embryonic lethality was calculated as the percentage of non-hatched embryos among the total number of embryos produced. Percent larval development was calculated as the percentage of larvae that reached the adult stage among the total number of hatched embryos, as previously described (Kawasaki et al., 2013). The broods of 10 mother hermaphrodites were examined to calculate the above values at each concentration of caffeine treatment.

Microarray analysis

Synchronized L1-stage worms were incubated on the plate containing 0 or $30 \mathrm{mM}$ caffeine in the absence of food, Escherichia coli strain OP50, at $20^{\circ} \mathrm{C}$ for $24 \mathrm{~h}$, and then total RNA was prepared from each worm sample. Poly-A RNA purification, reverse transcription, and labeling were performed as previously described (Reinke et al., 2000; 2004). Microarrays were constructed in Dr. Reinke's laboratory (Yale University), and the procedures and data analysis were performed as previously described (Reinke et al., 2000; 2004). Three independent microarray analyses were performed. The cyp genes that displayed more than two-fold differences with $p$-value $<0.05$ were selected.

\section{RT-PCR}

Synchronized L1-stage worms were grown on NGM agar plates with or without caffeine for 3 days. Total RNA was extracted from the worms with Trizol reagent (Sigma, USA) and purified, after which the first strand CDNA was synthesized by M-MLV reverse transcriptase (Gibco BRL, USA) using oligo-dT primer (Promega, USA). vit-6 cDNA product was then PCRamplified using vit- 6 forward primer, 5'-CAATCAATGTTGAACCACGC-3' and vit-6 reverse primer, 5'-CTCCTCCA-TTTGTGGTTGGT-3' (NM_068985). PCR was performed in $25 \mu \mathrm{l}$ reaction volumes with the following parameters: $94^{\circ} \mathrm{C}$ for $5 \mathrm{~min}$, followed by 25 cycles of $94^{\circ} \mathrm{C}$ for $1 \mathrm{~min}, 55^{\circ} \mathrm{C}$ for $45 \mathrm{~s}$, and $72^{\circ} \mathrm{C}$ for $1 \mathrm{~min}$, with final extension at $72^{\circ} \mathrm{C}$ for $10 \mathrm{~min}$. act-3 cDNA product was PCR-amplified as an internal control using act-3 forward primer, 5'-GAGGCCCAATCCAAGAGA-3' and act-3 reverse primer, 5'-TGTTGGAAGGTGGAGAGG-3' (NM_ 073416).

\section{Real time RT-PCR (qRT-PCR)}

Synchronized L1-stage or L4-stage worms were grown on NGM agar plates with or without caffeine for $24 \mathrm{~h}$. Total RNA was extracted from the worms with Trizol reagent (Sigma, USA), purified, and reverse transcribed with M-MLV reverse transcriptase (Gibco BRL, USA) using oligo-dT primer (Promega, USA) to synthesize the first strand cDNA. Respective cDNA products were PCR-amplified using the following primers: cyp35A2 F primer, 5'-TGAGCATTGCGGATTATGA-GAC-3', and cyp-35A2 R primer, 5'-CTCCAATATCGTTTCT-GACATCTC-3', for cyp-35A2 cDNA; cyp-35A3 F primer, 5'-GCTCAGAAAGAAATACGGCA-3', and cyp-35A3 R primer, 5'-GTTTATCTGCATATTTACCGCC-3', for cyp-35A3 cDNA; cyp-35A4 F primer, 5'-GAACTTGATGCTAGGTGCGC-3', and cyp-35A4 R primer, 5'-GCAGTTTCAATTGACGCATCC-3', for cyp-35A4 cDNA; cyp-35A5 F primer, 5'-AACAAGCTTGCTGATG-TTGCTC-3', and cyp-35A5 R primer, 5'-AATTTCAGCGCATC-TTGCATCC3', for cyp-35A5 cDNA. Primers for act-1 cDNA, which was used as an internal control, were act-1 $\mathrm{F}$ primer, 5'-CCAGGAATTGCTGATCGTATGCAGAA-3', and act-1 R primer, 5'TGGAGAGGGAAGCGAGGATAGA-3'. All PCR was performed in $25 \mu$ reaction volumes using Power SYBR ${ }^{\circledR}$ Green PCR Master Mix (Applied Biosystems, USA). The mRNA levels of each gene were averaged from triplicate measurements and normalized against that of act-1. Two or three independent experiments were performed.

\section{RNA interference (RNAi) analysis}

RNAi analysis was performed using the "RNAi-by-soaking" method, as described previously (Maeda et al., 2001). N2 worms were synchronized at the L1 larval stage in the absence of food, after which they were soaked for $24 \mathrm{~h}$ in each of the double-strand RNA solutions transcribed in vitro from respective cDNA templates, which were PCR-amplified from the cor- 
responding $L 4440$ vector feeding RNAi clones using T7 primer, 5'-GTAATACGACTCACTATAGGGC-3', and L4440 T7 primer, 5'-ATTAATACGACTCACTATAGGGA-3'. Worms were then retrieved and transferred to either caffeine-containing or control NGM plates, where they resumed development at $20^{\circ} \mathrm{C}$. After transfer, larval development was observed in $24 \mathrm{~h}$ intervals for a few days until most of the control worms reached the adult stage. We distinguished the larval stages as follows: L1, the smallest larvae less than $0.3 \mathrm{~mm}$; $L 2$, larvae larger than $\mathrm{L} 1$ (body length, 0.3-0.4 $\mathrm{mm}$ ) but have no characteristics of L3; L3, larvae containing a white spot in the vulva area (body length, 0.4-0.6 mm); L4, larvae containing a characteristic half-moonlike shape in the vulva area (body length, 0.6-0.8 mm); young adults (YA), worms with an opened vulva with no eggs in the uterus; adults (A), worms with an opened vulva with eggs in the uterus.

\section{Statistical analysis}

All experiments were repeated more than three times for statistical evaluation of data. $P$ values were calculated by Student's $t-$ test.

\section{RESULTS}

\section{Caffeine affected multiple developmental processes of C. elegans}

As a preliminary study, we examined growth rates of worms after treatment of $0,5,10,15,20$, and $30 \mathrm{mM}$ caffeine. We found that effects of caffeine were dosage-dependent, and determined three different concentrations of caffeine, 10, 20, and $30 \mathrm{mM}$ as mild, moderate, and critical doses, respectively. To examine the effects of caffeine on the developmental process of $C$. elegans, the L4-larval stage wild-type N2 hermaphrodites were treated with 10,20 , and $30 \mathrm{mM}$ of caffeine, after which the brood size of the progeny, embryonic lethality, and percent larval development were scored. As a result, brood size and percent larval development were decreased while embryonic lethality was increased, indicating that caffeine indeed inhibited the developmental processes of $C$. elegans at both embryonic and post-embryonic stages (Table 1). Treatment with $30 \mathrm{mM}$ caffeine caused more severe defects than 10 $\mathrm{mM}$ or $20 \mathrm{mM}$. At $30 \mathrm{mM}$ caffeine, brood size was decreased to $31.6 \%$ of the non-treated control, and $50.2 \pm 13.7 \%$ of the progeny were arrested as embryos. After hatching, only $22.7 \pm$ $5.78 \%$ of the larvae could develop into adults. These results indicate that caffeine affected multiple developmental processes of $C$. elegans in a dosage-dependent fashion.

\section{High dose of caffeine inhibited the early-stage larval development}

The effect of caffeine on the larval development of $C$. elegans was further examined by treating the larvae with 0,10 , or 30 $\mathrm{mM}$ of caffeine starting at the L1 stage (Fig. 1A). The development of about $900 \mathrm{~L} 1$ worms were observed at each caffeine concentration under dissecting microscope in $24 \mathrm{~h}$ intervals for $96 \mathrm{~h}$ at $20^{\circ} \mathrm{C}$, and the developmental stage of each individual was determined at each time point. The results were displayed as percent distribution of worms in each developmental stage in the population at each caffeine concentration and each time point, either as line graphs or as a table (Fig. 2 and Supplementary Table S2). This confirmed the dose-dependent effect of caffeine. That is, although $98.9 \pm 0.4 \%$ of the larvae eventually developed into adults after $96 \mathrm{~h}$ at $10 \mathrm{mM}$ caffeine, $86.1 \pm 3.4 \%$ of the larvae remained in the L1 stage after $96 \mathrm{~h}$ at $30 \mathrm{mM}$
Table 1. Effects of caffeine on C. elegans development are dosagedependent

\begin{tabular}{lccc}
\hline $\begin{array}{l}\text { Caffeine } \\
\text { treatment }\end{array}$ & Brood size & $\begin{array}{c}\text { Embryonic } \\
\text { lethality (\%) }\end{array}$ & $\begin{array}{c}\text { Percent larval } \\
\text { development (\%) }\end{array}$ \\
\hline $0 \mathrm{mM}$ & $250 \pm 28.1(100 \%)$ & $2.54 \pm 3.00$ & $95.2 \pm 5.63$ \\
$10 \mathrm{mM}$ & $185 \pm 22.2(74.0 \%)$ & $1.64 \pm 9,83$ & $76.9 \pm 15.1$ \\
$20 \mathrm{mM}$ & $167 \pm 57.5(66.8 \%)$ & $27.2 \pm 11.2$ & $66.0 \pm 11.3$ \\
$30 \mathrm{mM}$ & $79.1 \pm 27.3(31.6 \%)$ & $50.2 \pm 13.7$ & $22.7 \pm 5.78$ \\
\hline
\end{tabular}

10 synchronized L4-stage hermaphrodites were treated with different concentrations of caffeine after which brood size, F1 embryonic lethality, and $\mathrm{F} 1$ percent laval development were measured, as described in "Materials and Methods".

A
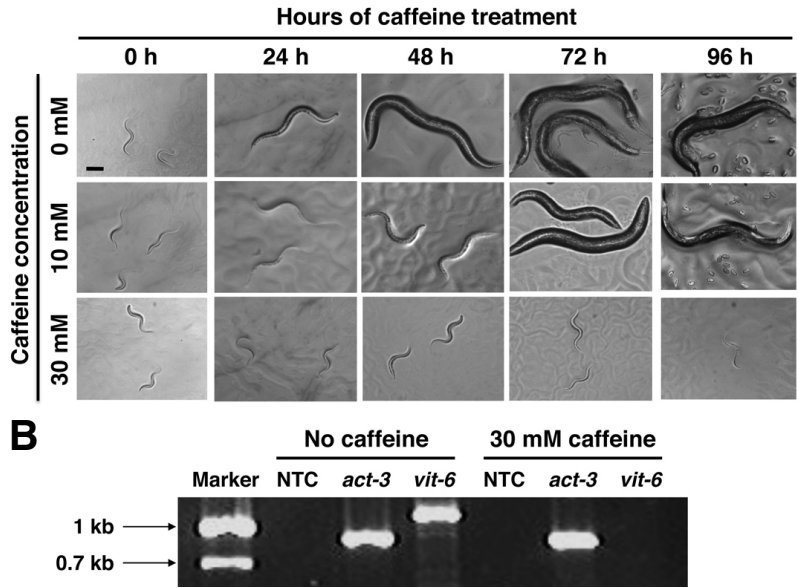

Fig. 1. C. elegans larval development in the presence or absence of caffeine. (A) Wild-type N2 worms synchronized at the L1 larval stage were cultured on NGM agar plates containing 0,10 , or 30 $\mathrm{mM}$ caffeine, and their development was observed in $24 \mathrm{~h}$ intervals for $96 \mathrm{~h}$ at $20^{\circ} \mathrm{C}$. Scale bar, $40 \mu \mathrm{m}$. (B) Absence of adult-stagespecific vit-6 gene expression in $30 \mathrm{mM}$ caffeine-treated larvae. N2 worms synchronized at the L1 lanval stage were cultured on NGM agar plates with or without $30 \mathrm{mM}$ caffeine for $72 \mathrm{~h}$ at $20^{\circ} \mathrm{C}$. Total RNA was extracted from the worms and expression of vit- 6 was examined by RT-PCR, with act-3 as an internal control. NTC, no template controls.

caffeine (Figs. 1A and 2; Supplementary Table S2). The effect of caffeine on larval development was irreversible when worms were treated with $30 \mathrm{mM}$ caffeine for over 2 days (data not shown). These results indicate that high doses of caffeine treatment are fatal to the development of early-stage larvae.

To confirm that the larvae arrested with the $30 \mathrm{mM}$ caffeine treatment indeed did not reach an adult stage, the expression of vit- 6 , a vitellogenin gene, was examined, as it is known that vit- 6 is expressed exclusively during the adult stage (Spieth and Blumenthal, 1985). Expression of vit- 6 mRNA was examined by RT-PCR with total RNA isolated from the worms grown for $72 \mathrm{~h}$ after hatching at $20^{\circ} \mathrm{C}$, with or without $30 \mathrm{mM}$ caffeine (Fig. 1B). A PCR-amplified vit- 6 cDNA band was detected only from the worm preparation grown without caffeine, not from that grown with $30 \mathrm{mM}$ caffeine, confirming that the $30 \mathrm{mM}$ caffeine 
Table 2. List of cyp genes induced by caffeine treatment*

\begin{tabular}{|c|c|c|c|c|}
\hline $\begin{array}{l}\text { Coding } \\
\text { sequence }\end{array}$ & Gene name & Chromosome & $\begin{array}{c}\text { Fold } \\
\text { increased }\end{array}$ & $p$-value \\
\hline C49G7.8 & сур-35A4 & 5 & 33.2 & 0.0113 \\
\hline K09D9.2 & сур-35A3 & 5 & 32.5 & 0.0211 \\
\hline K07C6.5 & сур-35A5 & 5 & 28.9 & 0.0071 \\
\hline C03G6.15 & сур-35A2 & 5 & 28.5 & 0.0084 \\
\hline B0213.15 & сур-34A9 & 5 & 10.0 & 0.0056 \\
\hline F08F3.7 & сур-14A5 & 5 & 8.3 & 0.0054 \\
\hline R04D3.1 & сур-14A4 & $x$ & 7.9 & 0.0181 \\
\hline K07C6.3 & сур-35В2 & 5 & 6.5 & 0.0233 \\
\hline $\mathrm{C} 5 \mathrm{OH} 11.15$ & сур-33с9 & 5 & 3.4 & 0.0027 \\
\hline C26F1.2 & сур-32A1 & 5 & 3.3 & 0.0125 \\
\hline F42A9.5 & сур-33Е2 & 4 & 2.9 & 0.0146 \\
\hline F41B5.2 & сур-33С7 & 5 & 2.8 & 0.0517 \\
\hline F14F7.3 & cyp-13A12 & 3 & 2.7 & 0.0348 \\
\hline K07C6.4 & сур-35B1 & 3 & 2.4 & 0.0062 \\
\hline K09A11.2 & сур-14A1 & $x$ & 2.4 & 0.0383 \\
\hline F44C8.1 & сур-33C4 & 5 & 2.4 & 0.04 \\
\hline B0213.12 & сур-34A7 & 5 & 2.4 & 0.051 \\
\hline C49C8.4 & сур-33Е1 & 4 & 2.2 & 0.0246 \\
\hline F41B5.7 & сур-33С6 & 5 & 2.2 & 0.0495 \\
\hline F42A9.4 & сур-33Е3 & 4 & 2.1 & 0.0161 \\
\hline K09A11.3 & сур-14A2 & $x$ & 2.0 & 0.0185 \\
\hline F41B5.4 & сур-33СЗ & 5 & 2.0 & 0.0337 \\
\hline T10B9.4 & сур-13A8 & 2 & 2.0 & 0.0128 \\
\hline E03E2.1 & сур-43A1 & $x$ & 2.0 & 0.0147 \\
\hline
\end{tabular}

*Only cyp genes that showed $>2$-fold increase, $p<0.05$ are listed as described in "Materials and Methods".

treatment arrested development at the larval stage.

L1-stage larvae were more susceptible to caffeine than later-stage larvae

Next, the effect of caffeine during different stages of larval development was examined by treating the worms with $30 \mathrm{mM}$ caffeine starting from the L1, L2, L3, L4, or young adult stage (Fig. 3). Worms treated with $30 \mathrm{mM}$ caffeine since the $\mathrm{L} 1$ stage were found to be mostly arrested at the L1 larval stage, as observed above. In contrast, the majority of the worms treated with the same concentration of caffeine after the L2 stage eventually developed into the adult stage, although their growth rate was significantly slower than the non-caffeine-treated controls and some worms also arrested as larvae (Fig. 3). These results indicate that although L1-stage larvae were the most susceptible to caffeine treatment, later-stage larvae were also partially susceptible.

To clarify that the larval developmental arrest after caffeine treatment was not caused by starvation due to blocking of pumping, we measured the pharyngeal pumping rate. Both L1stage worms and L4-stage worms cultured in the presence of $30 \mathrm{mM}$ caffeine for $24 \mathrm{~h}$ still maintained pumping although the rate was reduced to $69 \%$ and $64 \%$, respectively, of noncaffeine-treated controls (Supplementary Fig. S1). These results clearly indicate that the larval arrest after $30 \mathrm{mM}$ caffeine
A

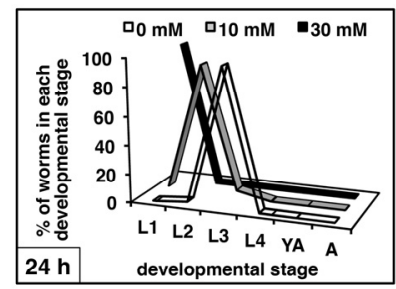

C

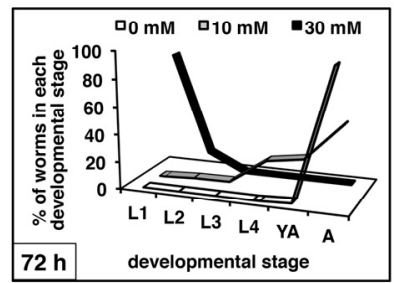

B

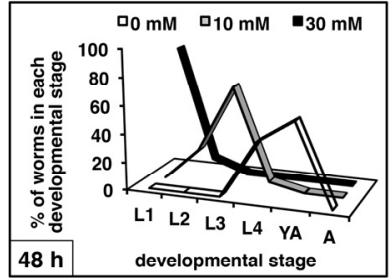

D

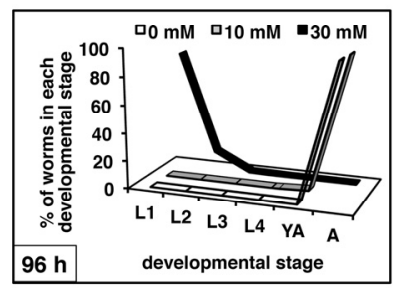

Fig. 2. Time course of $C$. elegans development in the presence or absence of caffeine. N2 worms synchronized at the L1 larval stage were cultured on NGM agar plates containing 0,10 , or $30 \mathrm{mM}$ caffeine, and the developmental stage of each individual was scored in $24 \mathrm{~h}$ intervals for $96 \mathrm{~h}$ at $20^{\circ} \mathrm{C}$ (A-D). Percent distribution of the worms at each developmental stage in each population was then plotted as a line graph at the indicated time points. The developmental time course was scored for about 900 individuals (triplicates of 300 individuals/plate) at each concentration of caffeine treatment. Average values at each time point for each developmental stage are summarized in Supplementary Table S2. L1 to L4, L1 to L4 larval stages; YA, young adult stage in which egg production had not yet started; $A$, adult stage in which egg production had already commenced.

treatment was not caused by starvation due to blocking of pumping although this reduction of pumping rate might have affected the slow growth rate of worms treated with caffeine since the L2, L3, and L4-stages (Fig. 3).

cyp-35A family genes were highly induced in the early-stage larvae upon caffeine treatment

To study the effects of caffeine treatment on global gene expression changes in $C$. elegans, microarray analysis was performed using the RNAs isolated from L1-stage larvae grown with or without caffeine. Among 65 cyp (cytochrome P450) genes tested, 29 were up- or down-regulated with $p<0.05$ (Supplementary Table S1), and 24 were up-regulated more than 2-fold (Table 2). Among them, expression of cyp-35A family genes was most prominently induced (more than 28.5 -fold). Therefore, further analysis was carried out on the effect of caffeine treatment on the gene expression of cyp-35A family genes, C49G7.8 (cyp-35A4), K07C6.5 (cyp-35A5), K09D9.2 (cyp-35A3), and C03G6.15 (cyp-35A2) by qRT-PCR analysis (Fig. 4, Table 3). It was confirmed that although cyp-35A family genes were not highly expressed in the worms grown in normal media without caffeine, the expression levels of the cyp-35A family genes were highly induced in the worms grown in the presence of $30 \mathrm{mM}$ caffeine, as shown by the microarray analysis (Fig. 4, Table 3). Notably, the levels of induction were more prominent in the L1 stage than in the L4 stage. From 217-fold (cyp-35A2) to 4,042-fold (cyp-35A5) induction was observed compared with the non-caffeine-treated controls in the L1 stage 
Table 3. Relative expression levels of cyp-35A genes in caffeine-treated L1 and L4 worms

\begin{tabular}{cccccc}
\hline Caffeine $(\mathrm{mM})$ & Treated stage & cyp-35A2 & cyp-35A3 & cyp-35A4 & cyp-35A5 \\
\hline 0 & L1 & 1.0 & 1.0 & 1.0 & 1.0 \\
30 & L1 & $217 \pm 0.6^{*}$ & $2168.0 \pm 18.8^{*}$ & $2180.9 \pm 4.9^{*}$ & $4042.2 \pm 45.4^{\star}$ \\
0 & L4 & 1.0 & 1.0 & 1.0 & 1.0 \\
30 & L4 & $8.4 \pm 0.3^{*}$ & $168.8 \pm 4.2^{*}$ & $1029.5 \pm 3.7^{*}$ & $97.9 \pm 1.7^{*}$ \\
\hline
\end{tabular}

Real time RT-PCR was performed with total RNA extracted from synchronized L1-stage or L4-stage worms grown with 30 mM caffeine or without caffeine for $24 \mathrm{~h}$ as described in "Materials and Methods". ${ }^{*} p<0.05$.
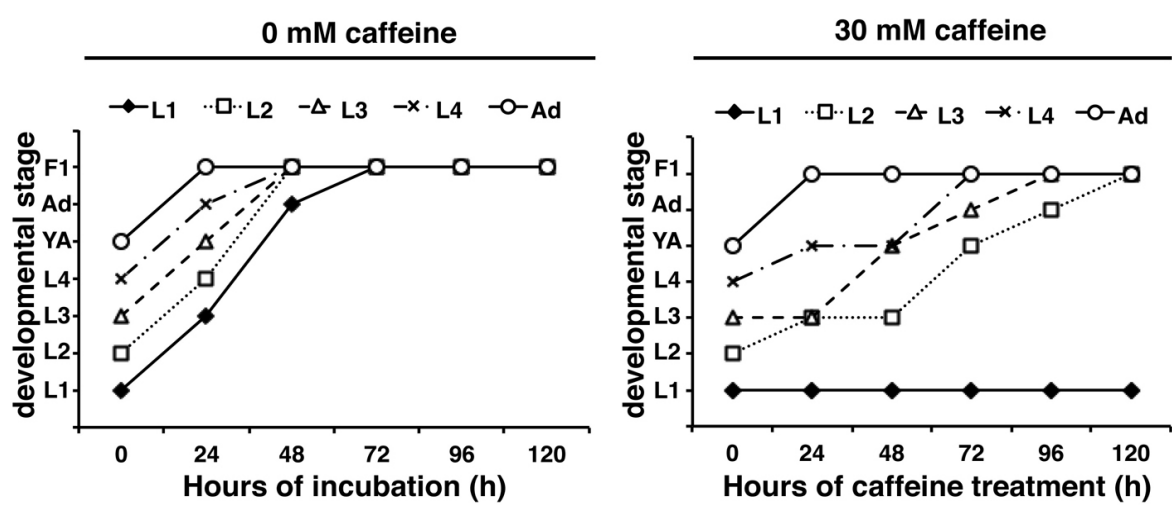

Fig. 3. N2 worms synchronized at each post-embryonic stage $(n=10)$ were cultured on NGM agar plates with or without $30 \mathrm{mM}$ caffeine, and the developmental stage shown by the majority of worms in each population was determined every $24 \mathrm{~h}$ for $120 \mathrm{~h}$ at $20^{\circ} \mathrm{C}$, then plotted as a line graph. L1 to L4, L1 to L4 larval stages; YA, young adult stage in which egg production had not yet started; Ad, adult stage in which egg production had already commenced; F1, F1 progeny were generated. Worms treated with $30 \mathrm{mM}$ caffeine since the L1 stage were developmentally arrested, whereas worms treated with the same concentration of caffeine after the $L 2$ stage eventually reached the adult stage.

\section{Comparison of the cyp-35 genes expression in L1 and L4 after $30 \mathrm{mM}$ caffeine treatment}

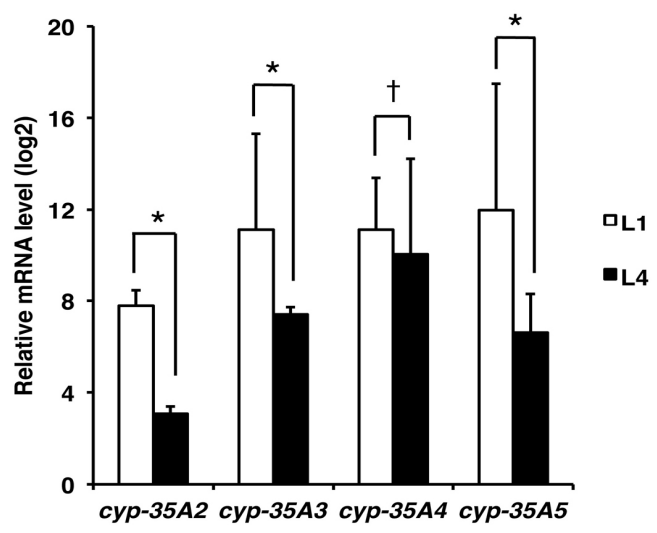

Fig. 4. Induction of cyp-35A family gene expression by caffeine treatment. N2 worms synchronized at either the L1 larval stage (about 10,000 worms) or the L4 larval stage (about 500 worms) were cultured on NGM agar plates with or without $30 \mathrm{mM}$ caffeine for $24 \mathrm{~h}$ at $20^{\circ} \mathrm{C}$. Total RNA was extracted from the worms and expression levels of the cyp-35A family genes cyp-35A2, cyp-35A3, cyp-35A4, and cyp-35A5 were measured by qRT-PCR. The relative mRNA expression levels of each gene after caffeine treatment are shown as the average values of triplicate measurements from two independent experiments, normalized to that the expression of act1. Expression levels were displayed as fold increase compared to the mRNA expression level of the same gene in the control worms without caffeine treatment using log 2 scales for the $Y$ axis. ${ }^{*} p<$ $0.05 .{ }^{\dagger} p>0.05$
(Fig. 4, Table 3). In contrast, the levels of induction at the $L 4$ stage were from 8.4-fold (cyp-35A2) to 1,029.5-fold (cyp-35A4). These results indicate that $c y p-35 A$ family genes are the most highly responsive $C$. elegans cyp genes to caffeine treatment, and that their induction levels are much higher in the L1 stage than in the L4 stage.

RNAi depletion of cyp-35A family genes partially rescued early-stage larval arrest caused by caffeine treatment

Synchronized L1-stage larvae were treated with RNAi of cyp$35 \mathrm{~A}$ family genes one-by-one or in quadruple combination, and then cultured in the presence of 10 or $30 \mathrm{mM}$ caffeine for $96 \mathrm{~h}$ at $20^{\circ} \mathrm{C}$. The developmental stage of each individual was then scored in $24 \mathrm{~h}$ intervals. The results were displayed as a percent distribution graph of the number of worms in each developmental stage at each time point (Fig. 5), and their average values were summarized in table form (Supplementary Table S3). When L1 larvae were cultured in the presence of $30 \mathrm{mM}$ caffeine without RNAi treatment (mock RNAi), the majority of the larvae $(94.0 \pm 0.02 \%)$ were arrested at the L1 stage and never developed into the next stage (Supplementary Table S3). However, after RNAi depletion of cyp-35A family genes one-byone or in quadruple combination, partial recovery from early larval arrest was observed (Fig. 5). Specifically, in the presence of $30 \mathrm{mM}$ caffeine, while only $6.0 \%$ of mock RNAi-treated L1 larvae eventually developed into L2- or L3-stage larvae, from $47.5 \%$ to $69.5 \%$ of the cyp-35A RNAi-treated L1 larvae were observed to develop into L2- or L3-stage larvae after $96 \mathrm{~h}$ (Fig. 5, Supplementary Table S3). Among the cyp-35A RNAi treatments, quadruple RNAi showed the most prominent recovery from the early larval arrest, suggesting a synergistic effect among the cyp-35A family members for the control of early 
Larval development in $30 \mathrm{mM}$ caffeine after cyp-35A RNAi

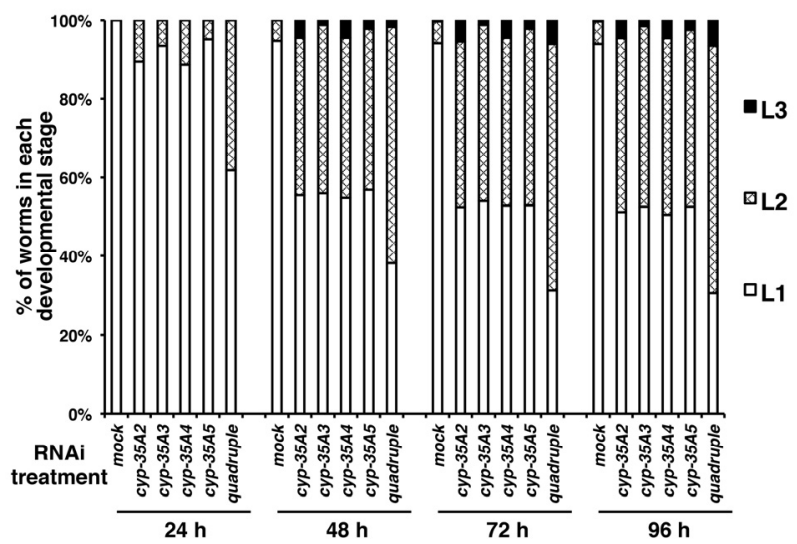

Fig. 5. RNAi of cyp-35A family genes partially rescued larval developmental arrest caused by $30 \mathrm{mM}$ caffeine treatment. N2 worms synchronized at the $\mathrm{L} 1$ larval stage were treated with soaking RNAi (single or quadruple RNAi) to deplete cyp-35A family gene activity. Worms were then transferred to $30 \mathrm{mM}$ caffeine-containing NGM plates and cultured at $20^{\circ} \mathrm{C}$. During the culture, larval development was scored in $24 \mathrm{~h}$ intervals for $96 \mathrm{~h}$, and percent distribution of worms in each developmental stage was displayed as a percent distribution graph for each RNAi treatment and time point. About 450 individuals (triplicates of 150 individuals/plate) were scored for each RNAi treatment. Average values of percent distribution of worms at each developmental stage are summarized in Supplementary Table S3.

larval development. Although the effect was not as prominent as that observed in $30 \mathrm{mM}$ caffeine, cyp-35A RNAi-treated larvae also showed partial recovery from growth retardation caused by treatment with $10 \mathrm{mM}$ caffeine (Supplementary Fig. S3). It was also confirmed that cyp-35A RNAi treatment did not affect larval development under normal culturing conditions without caffeine (Supplementary Fig. S2). These results suggest that the high-level induction of cyp-35A family genes in response to caffeine treatment is fatal to the early larval development of $C$. elegans.

We also examined RNAi of cyp-14A family genes, but caffeine effects on the larval development were not suppressed unlike RNAi of cyp-35A family genes (Supplementary Fig. S4). These results indicate that cyp-35A family genes have a specific function on caffeine response.

\section{DISCUSSION}

In humans, caffeine is mainly metabolized by CYP1A2 in the liver (Kot and Daniel, 2008), while neonates have a significantly reduced capacity for caffeine metabolism (Brent et al., 2011). This raises the question of whether insufficient expression of cyp genes is the major cause of developmental defects observed after caffeine intake during pregnancy, and suggests a possible correlation between developmental stage and capacity to induce cyp genes.

In this study, the effects of caffeine on developmental process and the expression of cyp genes were examined in $C$. elegans. Similar to human fetal development (Giannelli et al., 2003), caffeine was found to have a dose-dependent effect on the development of $C$. elegans, and higher concentrations caused severe developmental defects. It was also found that the first-stage larvae (L1) were more susceptible to caffeine than those in the later stages. In our study, we treated worms with $30 \mathrm{mM}$ caffeine to investigate the effects on larval development. In the previous study with lower concentrations of caffeine, positive effects such as extension of life span and protection against neurodegenerative diseases were reported (Dorsal et al., 2010; Sutphin et al., 2012). However, after 30 mM of caffeine treatment, majority of L1 larvae were arrested at the L1 stage without further development. These results suggest that L1-stage larvae might have not acquired an efficient caffeine metabolic system like young human infants. Approximately 80 different cytochrome P450 genes have been reported in the $C$. elegans KEGG genes database. They were grouped into three subfamilies based on similarity to mammalian orthologs CYP2, CYP3, and CYP4, which are drug-metabolizing enzymes in mammals (Gotoh, 1998). It was reported that $C$. elegans cyp genes were highly inducible by treatment with xenobiotics (Menzel et al., 2001; 2005). This implies that the CYP proteins in $C$. elegans also function for the detoxification of xenobiotic chemicals as mammalian CYP proteins do. It was found herein that genes of the cyp-35A family were highly induced by caffeine treatment. However, the observed levels of induction were much higher in the L1 stage than in the L4 stage (Fig. 4). These results suggest that the significant developmental defects in the L1 stage after caffeine treatment were not due to insufficient metabolic response to caffeine treatment. Rather, high-level induction of genes in the cyp-35A family during the L1 stage could be the cause of early larval stage developmental defects. This hypothesis was supported by the finding that the developmental defects caused by caffeine treatment were partially rescued after RNAi of cyp-35A family genes (Fig. 5). A similar finding was reported by another group (Menzel et al., 2005). They observed that cyp-35A genes were highly induced after treatment with xenobiotics, and furthermore, brood size was more decreased in wild-type $\mathrm{N} 2$ treated with xenobiotics than in worms in which all of the cyp-35A gene activities were depleted either by mutation or by RNAi. These findings suggest two possibilities. First, high-level induction of cyp-35A genes inhibits the development of $C$. elegans. Expression of cyp-35A genes was also induced by ethanol treatment, whereby stress genes were also induced (Kwon et al., 2004; Peltonen et al., 2012), which supports the view that high-level induction of cyp-35A genes can cause toxic effects. It was also reported that cyp$35 \mathrm{~A}$ family genes regulate fatty acid metabolism at the transcriptional level (Aarnio et al., 2011). The induction of cyp-35A genes may lead to up-regulation of fatty acid synthesis genes, thus resulting in abnormal fat storage, which subsequently affects the developmental processes. As suggested by the above cases, high-level induction of cyp-35A genes can interfere with the worm development. Second, induction of cyp-35A genes may not be a detoxification step for caffeine, rather, it may be involved in the accumulation of secondary metabolites from caffeine, which are toxic to the development of $C$. elegans especially when high-dose of caffeine was treated. This possibility needs to be examined further in future studies. The findings that mammalian cytochrome $\mathrm{P} 450$ also produces toxic metabolites supports this view. For example, mammalian cytochrome P450 can convert some polycyclic aromatic hydrocarbons and polychlorinated biphenyls to ultimate carcinogenic metabolites (Shou et al., 1996).

We consider that early larval developmental arrest observed after $30 \mathrm{mM}$ of caffeine treatment was not caused by starvation due to blocking of pumping because pumping was slowed but 
not completely blocked in this condition, although slow pumping rate might have affected growth rate of worms.

Two caffeine-resistant mutants were reported previously: osm-3(hf3), which was previously called caf-1(hf3), and che3(hf5), which was previously called caf-2(hf5). Both OSM-3 and CHE-3 are motor proteins in neurons. OSM-3 is a kinesin-like protein with function in axonal transport in $C$. elegans (Shakir et al., 1993). CHE-3 is a cytosolic dynein heavy chain functioning in ciliated sensory neurons (Wicks et al., 2000). The effects of caffeine were suppressed in these mutants (data not shown), suggesting that caffeine may not be sensed by sensory neurons in osm-3 or che-3 mutants.

In summary, caffeine can interfere with $C$. elegans early larval development. Although the cyp genes for caffeine metabolism are conserved between $C$. elegans and mammals, their functions during development may be different. High-level induction of cyp-35A genes in response to caffeine treatment during the early larval stages appears to be harmful to the development of $C$. elegans. Mammalian cyp genes are involved in the detoxification of caffeine, but they are expressed at very low levels in neonates; therefore, neonates can be more sensitive to caffeine than elder infants. There may be a biological reason why cyp genes are expressed at very low levels in human neonates.

Note: Supplementary information is available on the Molecules and Cells website (www.molcells.org).

\section{ACKNOWLEDGMENTS}

We thank Dr. V. Reinke (Yale University) and Dr. W. Chi (Yale University) for technical support of microarray analysis and data analysis. The $C$. elegans strain was provided by the Caenorhabditis Genetics Center. This study was supported by funds from Konkuk University in 2011 provided to Y.-H. Shim and by funds from the 2014 KU Brain Pool Program of Konkuk University to I. Kawasaki.

\section{REFERENCES}

Aarnio, V., Lehtonen, M., Storvik, M., Callaway, J.C., Lakso, M., and Wong, G. (2011). Caenorhabditis elegans mutants predict regulation of fatty acids and endocannabinoids by the CYP-35A gene family. Front. Pharmacol. 2, 12.

Brenner, S. (1974). The genetics of Caenorhabditis elegans. Genetics $77,71-94$.

Brent, R.L., Christian, M.S., and Diener, R.M. (2011). Evaluation of the reproductive and developmental risks of caffeine. Birth Defects Res. 92, 152-187.

Cnattingius, S., Signorello, L.B., Annerén, G., Clausson, B., Ekbom, A., Ljunger, E., Blot, W.J., McLaughlin, J.K., Petersson, G., Rane, A., et al. (2000). Caffeine intake and the risk of firsttrimester spontaneous abortion. N. Engl. J. Med. 343, 18391845.

Dostal, V., Roberts, C.M., and Link, C.D. (2010). Genetic mechanism of coffee extract protection in a Caenorhabditis elegans model of $\beta$-amyloid peptide toxicity. Genetics 186, 857-866.

Giannelli, M., Doyle, P., Roman, E., Pelerin, M., and Hermon, C. (2003). The effect of caffeine consumption and nausea on the risk of miscarriage. Paediatr. Perinat. Epidemiol. 17, 316-323.

Gilbert, R.M., Marshman, J.A., Schweider, M., and Berg, R. (1976). Caffeine content of beverages as consumed. Can. Med. Assoc. J. 114, 205-208.

Gotoh, O. (1998). Divergent structures of Caenorhabditis elegans cytochrome P450 genes suggest the frequent loss and gain of introns during the evolution of nematodes. Mol. Biol. Evol. 15, 1447-1459.

Hoyt, A.T., Browne, M., Richardson, S., Romitti, P., Druschel, D.
(2014). Maternal caffeine consumption and small for gestational age births: results from a population-based case-control study. Matern. Child Health J. 18, 1540-1551.

Kawasaki, I., Jeong, M.W., Yun, Y.J., Shin, Y.K., and Shim, Y.H. (2013). Cholesterol-responsive metabolic proteins are required for larval development in Caenorhabditis elegans. Mol. Cells 36, 410-416.

Knutti, R., Rothweiler, H., and Schlatter, C. (1981). Effect of pregnancy on the pharmacokinetics of caffeine. Eur. J. Clin. Pharmacol. 21, 121-126.

Kot, M., and Daniel, W.A. (2008). The relative contribution of human cytochrome P450 isoforms to the four caffeine oxidation pathways: an in vitro comparative study with cDNA-expressed P450s including CYP2C isoforms. Biochem. Pharmacol. 76, 543-551

Kwon, J.Y., Hong, M., Choi, M.S., Kang, S., Duke, K., Kim, S., Lee, S., and Lee J. (2004). Ethanol-response genes and their regulation analyzed by a microarray and comparative genomic approach in the nematode Caenorhabditis elegans. Genomics 83, 600-614

Maeda, I., Kohara, Y., Yamamoto, M., and Sugimoto, A. (2001). Large-scale analysis of gene function in Caenorhabditis elegans by high-throughput RNAi. Curr. Biol. 11, 171-176.

Menzel, R., Bogaert, T., and Achazi, R. (2001). A systematic gene expression screen of Caenorhabditis elegans cytochrome P450 genes reveals CYP35 as strongly xenobiotic inducible. Arch. Biochem. Biophys. 395, 158-168.

Menzel, R., Rödel, M., Kulas, J., and Steinberg, C.E.W. (2005). CYP35: xenobiotically induced gene expression in the nematode Caenorhabditis elegans. Arch. Biochem. Biophys. 438, 93102

Nehlig, A. (1999). Are we dependent upon coffee and caffeine? A review on human and animal data. Neurosci. Biobehav. Rev. 23 563-576.

Nelson, D.R., Zeldin, D.C., Hoffman, S.M.G., Maltais, L.J., Wain, H.M., Nebert, D.W. (2004). Comparison of cytochrome P450 (CYP) genes from the mouse and human genomes, including nomenclature recommendations for genes, pseudogenes and alternative-splice variants. Pharmacogenetics. 14, 1-18.

Pletonen, J., Aarnio, V., Heikkinen, L., Lakso, M., and Wong, G (2013). Chronic ethalnol exprosure increases cytochrome P-450 and decreases activated in blocked unfolded protein response gene family transcripts in Caenorhabditis elegans. J. Biochem. Mol. Toxicol. 27, 219-228.

Reinke, V., Smith, H.E., Nance, J., Wang, J., Van Doren, C., Begley, R., Jones, S.J.M., Davis, E.B., Schere,r St., Ward, S. et al. (2000). A global profile of germline gene expression in C. elegans. Mol. Cell 6, 605-616.

Reinke, V., Gil, I.S., Ward, S., and Kazmer, K. (2004). Genome-side germline-enriched and sex-biased expression profiles in Caenorhabditis elegans. Development 131, 311-323.

Shakir, M.A., Fukushige, T., Yasuda, H., Miwa, J., and Siddiqui, S.S. (1993). C. elegans osm-3 gene mediating osmotic avoidance behavior encodes a kinesin-like protein. Neuroreport 4, 891-894.

Shou, M., Gonzalez, F.J., and Gelboin, H.V. (1996). Stereoselective epoxidation and hydration at the K-region of polycyclic aromatic hydrocarbons by cDNA-expressed cytochromes P450 1A1, 1A2, and epoxide hydrolase. Biochemistry 35, 15807-15813.

Speith, J., and Blumenthal, T. (1985). The Caenorhabditis elegans vitellogenin gene family includes a gene encoding a distantly related protein. Mol. Cell. Biol. 5, 2495-2501.

Sutphin, G.L., Bishop, E., Yanos, M.E., Moller, R.M., and Kaeberlein, M. (2012). Caffeine extends life span, improves healthspan, and delays age-associated pathology in Caenorhabditis elegans. Longev. Healthspan 1, 1-9.

The C. elegans Sequencing Consortium. (1998). Genome sequence of the nematode C. elegans: a platform for investigating biology. Science 282, 2012-2018.

Weinberg, B.A., and Bealer, B.K. (2002). The caffeine advantage (NY, USA: The Free press).

Wicks, S.R., de Vries, C.J., van Luenen, H.G.A.M., and Plasterk, R.H.A. (2000). CHE-3, a cytosolic dynein heavy chain, is required for sensory cilia structure and function in Caenorhabditis elegans. Dev. Biol. 221, 295-307. 